EGU21-7985, updated on 17 May 2021

https://doi.org/10.5194/egusphere-egu21-7985

EGU General Assembly 2021

(c) Author(s) 2021. This work is distributed under

the Creative Commons Attribution 4.0 License.

\title{
Experimental rooftop rainwater harvesting by shallow well infiltration - A case study from the Duna-Tisza Interfluve, Hungary
}

\author{
Zsóka Szabó ${ }^{1,2}$, Daniele Pedretti ${ }^{3}$, Marco Masetti ${ }^{3}$, Tibor Ridavits ${ }^{1,2}$, Endre Csiszár ${ }^{4}$, and Judit Mádl- \\ Szőnyi ${ }^{1,2}$ \\ ${ }^{1}$ Department of Geology, Eötvös Loránd University, Budapest, Hungary (szazsoka@caesar.elte.hu) \\ ${ }^{2}$ József and Erzsébet Tóth Endowed Hydrogeology Chair, Eötvös Loránd University, Budapest, Hungary \\ ${ }^{3}$ Dipartimento di Scienze della Terra 'A. Desio', Università degli Studi di Milano, Milan, Italy \\ ${ }^{4}$ BÁCSVÍZ Water and Sewer Services Ltd., Kecskemét, Hungary
}

In the Duna-Tisza Interfluve area, groundwater levels have declined significantly in the last decades, due to anthropogenic activities (e.g. water abstraction, canalization, and forestation) and climate change. In the past, several replenishment plans have been prepared, involving large, cross-regional technical investments, but have not been implemented due to the lack of adequate financial resources and environmental concerns. The aim of this study is to demonstrate a local scale solution by experimental research, which has several environmental and economic benefits and could contribute to ease the water shortage of the area.

Three approaches were used during the experimental research: (i) on-site field observations and measurements, (ii) time series analyses of the monitored data and (iii) transient numerical simulations to understand on-site processes. A field experiment was set up to lead rainwater from the roof of a family house to the dug well in the yard. Furthermore, two observation wells were established where the water level, temperature and electrical conductivity were recorded every half hour. Water samples were taken from the dug well and the monitoring wells for laboratory measurements. Precipitation was measured on a daily basis. The effects of shallow water injection on water level and water quality have been monitored for a year and the project is planned to be continued for at least one more year. In the second step, geomathematical methods have been applied to analyze time-series data and assess the effects of injected water on water levels and water quality. Moreover, a transient MODFLOW model was built (i) to evaluate the impact of the injected roof water on the groundwater level, (ii) to separate the influence of natural infiltration from the injected water, and (iii) to better understand the seasonal differences related to artificial and natural infiltration processes.

The obtained results can help to understand the effects of rainwater harvesting through shallow well infiltration, provide background information for further numerical simulations and contribute to expand the design of similar systems on settlement and regional level. In the Duna-Tisza Interfluve, rooftop rainwater harvesting and Managed Aquifer Recharge can be effective tools for climate change adaptation and increasing groundwater resilience.

This research is part of a project that has received funding from the European Union's Horizon 
2020 research and innovation programme under grant agreement No 810980. 